\title{
A practical Jointed Approach to Functionally Graded Structures by Differential Transform Method
}

\author{
Ibrahim Keles ${ }^{1, *}$, Vedat Suat Erturk ${ }^{2}$ \\ 'Department of Mechanical Engineering, Amasya University,05100, Amasya, Turkey \\ ${ }^{2}$ Department of Mathematics, Ondokuz Mayis University, 55139, Samsun, Turkey
}

ORCID: I. Keles (0000-0001-2345-6789), V.S. Erturk (0000-0001-2345-6789)

\begin{abstract}
In this study, a practical jointed approach in the static vibration investigation of functionally graded material (FGM) structures under internal pressure is applied by differential transform method (DTM). The FGM material consist of isotropic material that show exponential variation in the thickness. The ratio of Poisson is taken as a constant. Displacement and stress distributions due to non-homogeneous constant are intended. Stress distribution dependent on the homogeneity parameter is computed and the results obtained for cylindrical and spherical structures were compared with finite element method (FEM). The inhomogeneity parameter is empirically regulated, with a continuously varying volume fraction of the constituents. The parameters for homogeneity were randomly selected to show displacement and stress distributions.
\end{abstract}

Keywords: Functionally graded materials, Structural elements, Initial value problems, Differential transform method (DTM)

\section{INTRODUCTION}

The structural elements of the pressure vessels used in engineering areas such as aerospace and petroleum are important in engineering applications such as cylinder and sphere. As a result, the internal loads are one of the main problems of industrial structures. It may lead to stress gradient and / or cracked nuclei occurring in the stress distribution of the specified loads. By the analysis of the structures under the influence of the internal pressure, it facilitates the determination of the density of the points affected by the stress and the unsuitable stress distributions. Previous research has provided analytical solutions for homogeneous isotropic and orthotropic members. Tranter [1], Mirsky [2], Klosner and Dym [3], Ahmed [4] and Ghosh [5] have pioneered their work in the cylinders, discs and spheres due to axial symmetry.

The functional graded materials (FGM) are more advanced structural materials in determining the material properties in the direction of the thickness in the solution of problems due to the composite materials interfaces. In recent years, thermal stresses, free and forced vibration analysis have been successfully applied to mechanical problems with different structures such as FGMs, circular fins [6], irregular piezoelectric and nonhomogeneous rods [7-9] and functionally graded beams [10]. Güven and Baykara [11] explained the mechanical stress distribution of the isotropic functional grade thick walled sphere under the influence of internal pressure. Tutuncu and Ozturk [12] presented exact solutions in the form of stresses occurring in functionally graded pressure vessels. A study close to this work was also published by Horgan and Chan [13]. Obata and Noda [14] submitted the studies of constant thermal stresses in order to understand the design of the functional graded thickwalled spheres and cylinders and the effects of the stresses. Tutuncu and Temel [15] functional-grade hollow cylinders have solved the displacements and stresses of the disc and spheres using an analytical method. Differential equations and systems obtained in the analysis of stress distributions are not easy to solve with analytical methods. In most cases, this is impossible. Therefore, numerical methods are applied in case of large equation systems, non-linearity and complex geometry. Therefore, it is a good option to select a numerical method to determine the stress distributions of FGM cylinders and spheres.

In many problems of physics and engineering, linear and non-linear systems of first or higher order differential equa-
${ }^{*}$ Corresponding authour

Email: ibrahim.keles@amasya.edu.tr
European Mechanical Science, September 2019; 3(3): 118-124 doi: https://doi.org/10.26701/ems.568318

Received: May 21, 2019

Accepted: September 4, 2019 
tions are presented. Many methods are used in the solution of these systems. In the recent years, more useful methods based on serial solution have been introduced. In this way, convergent results can be obtained more quickly. One of these methods is the differential transform method (DTM). DTM was first introduced by Zhou [16]. It was used to solve both linear and non-linear initial value problems in electrical propagation analysis. The major advantage of this method is that it can be easily applied using initial conditions in linear or nonlinear ordinary and partial differential equations and systems of equations. DTM is one of the effective mathematical methods used to solve ordinary and partial differential equations. This method is a semi-analytical method that uses Taylor's series expansion. By using DTM, it is possible to obtain very convergent and accurate results and to obtain exact solutions for differential or combined differential equations [17]. By using this method, valid differential equations can be reduced to repetition relations and boundary conditions can be transformed into a group of algebraic equations. Some researchers have successfully applied the DTM in solving the eigenvalue problems [1820]. Yeh et al. [21] evaluated free vibration of the rectangular thin plates, using a hybrid method which merges the finite difference and the differential transformation techniques. Yeh et al. [22] studied large deflections of the orthotropic rectangular thin plates, engaging a like hybrid method. Shin et al. [23] utilized the universal differential quadrature approach and the DTM for vibration analysis of circular arches with variable cross-section.

The solution of the non-linear vibration problem was conducted by Chen et al. [24]. Chen and Ho [25] solved partial differential equations by two- dimensional differential transform method. For some eigenvalue problems, the author who applied DTM was Ref. [26]. With the method as a powerful tool in the literature, differential equations, differential equations, fluid mechanics, and many other areas of high-grade boundary value problems have produced solutions [27-30].

In this study, we present the application of DTM as a numerical method for stress and displacement solutions of FGM cylinders and spheres of variable thickness. As a material feature, the change in thickness of the modulus of elasticity $\left(E(r)=E_{0} e^{\beta r}\right)$ is defined. The results were compared with FEM compared with the results. The non-homogeneous $\beta$ values were used to indicate the distribution over the stress. The inhomogeneity constant $\beta$ used in the study does not represent a specific material. The accuracy of the numerical method is tested for an attached analytical solution for a homogeneous cylinder with a constant elasticity modulus and a poison ratio. A comparison was made with FEM (ANSYS) to determine the accuracy and effectiveness of the numerical method.

\section{BASIC EQUATION}

The stress and displacement distribution in a thick-walled hollow cylinder will be considered as the inner radius $R_{i}$ and the outer radius $R_{0}$. The elasticity modules vary throughout the thickness.

\subsection{Basic Formulation of FGM Cylinders}

Strain-displacement and basic equations considering the assumption of plane strain are [12]

$$
\begin{aligned}
& \varepsilon_{r}=\frac{d u}{d r}, \quad \varepsilon_{\theta}=\frac{u}{r}, \\
& \sigma_{r}=C_{11}(r) \varepsilon_{r}+C_{12}(r) \varepsilon_{\theta}, \\
& \sigma_{\theta}=C_{12}(r) \varepsilon_{r}+C_{11}(r) \varepsilon_{\theta},
\end{aligned}
$$

where, with $v_{0}$ the Poisson's ratio,

$$
\begin{aligned}
& C_{11}(r)=\left(\frac{E_{0}\left(1-v_{0}\right)}{\left(1+v_{0}\right)\left(1-2 v_{0}\right)}\right) e^{\beta r} \text { and } \\
& C_{12}(r)=\left(\frac{E_{0} v_{0}}{\left(1+v_{0}\right)\left(1-2 v_{0}\right)}\right) e^{\beta r} .
\end{aligned}
$$

The only nontrivial equilibrium equation under assumptions can be inscribed in the following form [5],

$$
\frac{d \sigma_{r}}{d r}+\frac{\left(\sigma_{r}-\sigma_{\theta}\right)}{r}=0
$$

Using Eqs.(1)-(3), basic equation of radial displacement becomes

$$
\begin{aligned}
& u^{\prime \prime}+\frac{1}{r}(1+r \beta) u^{\prime}+\frac{(v \beta r-1)}{r^{2}} u=0 \\
& \text { where, } v=\frac{C_{12}(r)}{C_{11}(r)}=\frac{v_{0}}{1-v_{0}} .
\end{aligned}
$$

with boundary conditions in radial directions

$$
\left.\sigma_{r}\right|_{r=R_{i}}=-P \text { and }\left.\sigma_{r}\right|_{r=R_{0}}=0
$$

\subsection{Basic Formulation of FGM Spheres}

The strain-displacement and constitutive equations for spheres case are [12],

$$
\begin{aligned}
& \varepsilon_{r}=\frac{d u}{d r} \\
& \varepsilon_{\theta}=\varepsilon_{\varphi}=\frac{u}{r} \\
& \gamma_{r \theta}=\gamma_{r \varphi}=\gamma_{\theta \varphi}=0 \\
& \sigma_{r}=C_{11}(r) \varepsilon_{r}+C_{12}(r) \varepsilon_{\theta}+C_{12}(r) \varepsilon_{\varphi} \\
& \sigma_{\theta}=\sigma_{\varphi}=C_{12}(r) \varepsilon_{r}+C_{11}(r) \varepsilon_{\theta}+C_{12}(r) \varepsilon_{\varphi}
\end{aligned}
$$

with $v_{0}$ being the Poisson's ratio,

$$
\begin{aligned}
& C_{11}(r)=\left(\frac{E_{0}\left(1-v_{0}\right)}{\left(1+v_{0}\right)\left(1-2 v_{0}\right)}\right) e^{\beta r} \text { and } \\
& C_{12}(r)=\left(\frac{E_{0} v_{0}}{\left(1+v_{0}\right)\left(1-2 v_{0}\right)}\right) e^{\beta r}
\end{aligned}
$$

The only nontrivial equilibrium equation is [12]

$$
\frac{d \sigma_{r}}{d r}+\frac{2\left(\sigma_{r}-\sigma_{\theta}\right)}{r}=0
$$

Similarly, using Eqs. (7)-(8), according to stress equilibrium equations, the governing equation of displacement becomes

$$
u^{\prime \prime}+\frac{1}{r}(\beta r+2) u^{\prime}+\frac{(2 v \beta r-2)}{r^{2}} u=0
$$


where $v=\frac{C_{12}(r)}{C_{11}(r)}=\frac{v_{0}}{1-v_{0}}$.

\section{FUNDAMENTALS OF DTM}

$y(x)$ : original function

$Y(k)$ : the transformed function.

$$
Y(k)=\frac{1}{k !}\left(\frac{d^{k} y(x)}{d x^{k}}\right)_{x=x_{0}} .
$$

The inverse differential transform of $Y(k)$ is defined as

$$
y(x)=\sum_{k=0}^{\infty} Y(k)\left(x-x_{0}\right)^{k} .
$$

Putting together Eqs. (12) and (13), we get

$$
y(x)=\sum_{k=0}^{\infty} \frac{1}{k !}\left(\frac{d^{k} y(x)}{d x^{k}}\right)_{x=x_{0}} .\left(x-x_{0}\right)^{k} .
$$

When we look at Eq. (8), it is seen that the notion of differential transformation is caused by the expansion of Taylor series. But, it is a method that does not calculate its derivatives symbolically. In the present embodiments, the function $y(x)$ is represented by a finite power series and Eq.(14) can be rewritten as follows

$$
y(x)=\sum_{k=0}^{N} \frac{1}{k !}\left(\frac{d^{k} y(x)}{d x^{k}}\right)_{x=x_{0}} .\left(x-x_{0}\right)^{k} .
$$

Eq. (15) suggest that

$$
\sum_{k=N+1}^{\infty} Y(k)\left(x-x_{0}\right)^{k}
$$

is negligibly small, where $N$ is series size.

Mathematical operations done by DTM are listed in Table 1.

Table 1. Operations of DTM

Original function Transformed function

$$
\begin{array}{ll}
f(x)=g(x) \pm h(x) & F(k)=G(k) \pm H(k) \\
f(x)=c g(x) & F(k)=c G(k) \\
f(x)=g(x) h(x) & F(k)=\sum_{l=0}^{k} G(l) H(k-l) \\
f(x)=\frac{d^{m} g(x)}{d x^{m}} & F(k)=\frac{(k+m) !}{k !} G(k+m) \\
f(x)=x^{m} & F(k)=\delta(k-m)=\left\{\begin{array}{l}
1 k=m \\
0 k \neq m
\end{array}\right.
\end{array}
$$

\section{FORMULATION WITH DTM AND SOLUTION PROCEDURE}

\subsection{Cylindrical Structures}

The resulting differential equation that is presented in Eq.

(5) basic DTM rules are converted to provide the following repetition:

$$
U(k+2)=-\frac{H_{1}(k)+H_{2}(k)}{(k+1)(k+2)},
$$

where $U(k), H_{1}(k)$ and $H_{2}(k)$ correspond to the differential transforms of $u(r)$, the functions

$$
h_{1}(r)=\frac{r(\beta r+1)}{r^{2}}
$$

and

$$
h_{2}(r)=\frac{v \beta r-1}{r^{2}}
$$

respectively. In addition, DTM is applied to Eq.(5) using the theorems given in Table 1 and the following converted boundary conditions are obtained from

$$
\begin{aligned}
& \left.\sigma_{r}\right|_{r=R_{i}}=-P \text { and }\left.\sigma_{r}\right|_{r=R_{0}} \\
& e^{\beta \cdot \frac{6}{10}}\left(U(1)+v \cdot \frac{U(0)}{\frac{6}{10}}\right)=-P \text { at } r=\frac{6}{10} \\
& e^{\beta}\left(\sum_{k=1}^{N} k U(k)\left(1-\frac{6}{10}\right)^{k-1}+v \cdot \frac{\sum_{k=0}^{N} U(k)\left(1-\frac{6}{10}\right)^{k}}{1}\right)=0 \text { at } r=1 .
\end{aligned}
$$

Utilizing Eq.(6), $\quad H_{1}(k)$ values for arbitrary $\mathrm{k}$ can easily evaluated in terms of $\beta$. These values are obtained by using the Mathematica computer package as follows:

$$
\begin{aligned}
& H_{1}(0)=\frac{25}{9}\left(\frac{3}{5}+\frac{9 \beta}{25}\right), \\
& H_{1}(1)=-\left(\frac{250}{27}\right)\left(\frac{3}{5}+\frac{9 \beta}{25}\right)+\frac{25}{9}\left(1+\frac{6 \beta}{5}\right), \\
& H_{1}(2)=\frac{1}{2}\left[\frac{1250}{27}\left(\frac{3}{5}+\frac{9 \beta}{25}\right)+\frac{50 \beta}{9}-\frac{500}{27}\left(1+\frac{6 \beta}{5}\right)\right],
\end{aligned}
$$

and so on. Similarly, using Eq. (12), $H_{2}(k)$ values for arbitrary $k$ can easily evaluated in terms of $\beta$ and $\nu$ as follows:

$$
\begin{aligned}
& H_{2}(0)=\frac{25}{9}\left(-1+\frac{3 \beta v}{5}\right), \\
& H_{2}(1)=\frac{25 \beta v}{9}-\frac{250}{27}\left(-1+\frac{3 \beta v}{5}\right) \\
& H_{2}(2)=\frac{1}{2}\left[-\frac{500 \beta v}{27}+\frac{1250}{27}\left(-1+\frac{3 \beta v}{5}\right)\right], \text { and so on. }
\end{aligned}
$$

Applying the repetition relation Eq.(17) and the transformed boundary conditions Eqs.(20)-(21), and by using the inverse transform rule in Eq.(13), the first few components of the differential transform solution for $u(r)$ is derivatived as follows:

$$
\begin{aligned}
& u(r)=A+\left(r-\frac{3}{5}\right) B+\left[\left(\frac{25}{18}-\frac{5 \beta v}{3}\right) A-\left(\frac{5}{6}+\frac{\beta}{2}\right) B-\right]\left(r-\frac{3}{5}\right)^{2} \\
& +\left[\left(-\frac{125}{54}-\frac{25 \beta}{54}+\frac{25 \beta v}{27}+\frac{5 \beta^{2} v}{18}\right) A+\left(\frac{25}{18}+\frac{5 \beta}{9}+\frac{\beta^{2}}{6}-\frac{5 \beta v}{18}\right) B\right]\left(r-\frac{3}{5}\right)^{3}+;
\end{aligned}
$$

where, according to Eq.(6), $A=U(0)=u\left(\frac{6}{10}\right) \quad$ and $B=U(1)=u^{\prime}\left(\frac{6}{10}\right)$. The constants $A$ and $B$ are estimated from the boundary conditions given in Eqs.(20)-(21). These values are not given here because of their lengthy.

Stress statements take the following form 


$$
\begin{aligned}
& \sigma_{r}=\left(\varepsilon_{r}+v \varepsilon_{\theta}\right) e^{\beta r} \\
& \sigma_{\theta}=\left(v \varepsilon_{r}+\varepsilon_{\theta}\right) e^{\beta r}
\end{aligned}
$$

\subsection{Spherical Structures}

Unlike cylindrical structural elements, it is the variable layers in the differential equation. By following the same steps, displacement solutions can be expressed using boundary condition.

$\left.\sigma_{r}\right|_{r=R_{i}}=-P$ and $\left.\sigma_{r}\right|_{r=R_{0}}=$ at Some components of DTM for $u(r)$ is derived as follows:

$$
\begin{aligned}
& u(r)=A+\left(r-\frac{3}{5}\right) B+\left[\left(\frac{25}{9}-\frac{5 \beta v}{3}\right) A-\left(\frac{5}{3}+\frac{\beta}{2}\right) B-\right]\left(r-\frac{3}{5}\right)^{2} \\
& +\left[\left(-\frac{500}{81}-\frac{25 \beta}{27}+\frac{25 \beta v}{9}+\frac{5 \beta^{2} v}{9}\right) A\right. \\
& \left.+\left(\frac{100}{27}+\frac{10 \beta}{9}+\frac{\beta^{2}}{6}-\frac{5 \beta v}{9}\right) B\right]\left(r-\frac{3}{5}\right)^{3}+\because
\end{aligned}
$$

\section{PROVISION OF SOLUTION METHOD}

The efficiency and reality of numerical methods is first checked with the analytical results obtained for thick walled homogeneous vessels with $E=200 \mathrm{GPa}, \nu=0.3$ and $R_{0}$ $=2.0,[15]$. This benchmark solution is given in the Appendix expressed using the notation of the present study. The radial displacement $u$, radial stress $\sigma_{r}$ and hoop stress $\sigma_{\theta}$ are calculated at 11 collocation points through the thickness (10 divisions) and comparisons are given in Table 2. It is clearly seen from comparison that the results are in good agreement with each other, which demonstrate the validity of the numerical solutions used in this work.

Table 2. Comparison of DTM results with analytical results for homogene-

\begin{tabular}{|c|c|c|c|c|c|c|}
\hline \multirow{2}{*}{$r$} & \multicolumn{2}{|c}{$u$} & \multicolumn{2}{c}{ ous cylinder. } \\
& \multicolumn{2}{|c}{$\sigma_{r}(\mathrm{GPa})$} & \multicolumn{2}{c|}{$\sigma_{\theta}(\mathrm{GPa})$} \\
\cline { 2 - 7 } & Analytical & DTM & Analytical & DTM & Analytical & DTM \\
\hline 1.0 & 0.009533 & 0.009532 & -1. & $-0,999999$ & 1.666667 & 1.666666 \\
\hline 1.1 & 0.008832 & 0.008831 & -0.768595 & -0.768594 & 1.435262 & 1.435261 \\
\hline 1.2 & 0.008262 & 0.008261 & -0.592593 & -0.592592 & 1.259259 & 1.259258 \\
\hline 1.3 & 0.007793 & 0.007792 & -0.455621 & -0.455620 & 1.122288 & 1.122287 \\
\hline 1.4 & 0.007404 & 0.007403 & -0.346939 & -0.346938 & 1.013605 & 1.013604 \\
\hline 1.5 & 0.007078 & 0.007077 & -0.259259 & -0.259258 & 0.925926 & 0.925925 \\
\hline 1.6 & 0.006803 & 0.006802 & -0.187499 & -0.187498 & 0.854167 & 0.854166 \\
\hline 1.7 & 0.006571 & 0.006570 & -0.128028 & -0.128027 & 0.794694 & 0.794693 \\
\hline 1.8 & 0.006375 & 0.006374 & -0.078189 & -0.078188 & 0.744856 & 0.744855 \\
\hline 1.9 & 0.006208 & 0.006207 & -0.036011 & -0.036010 & 0.702678 & 0.702677 \\
\hline 2.0 & 0.006067 & 0.006066 & 0. & 0.000000 & 0.666667 & 0.666666 \\
\hline & & & & & & \\
\hline
\end{tabular}

\section{RESULTS}

Figures $(1,6)$ show comparison of the methods and evolution of radial stress $\sigma_{r}$, circumferential stress $\sigma_{\theta}$ and radial displacement $U^{*}=C_{11}^{0} u_{r}$ for

$C_{11}^{0}=\left(\frac{E_{0}\left(1-v_{0}\right)}{\left(1+v_{0}\right)\left(1-2 v_{0}\right)}\right), v=0.3, R_{i}=0.6, R_{0}=1.0$

and $\beta=1,2,3$. The boundary conditions for stresses are as- sumed as $\sigma_{r}(0.6)=-1 ; \sigma_{r}(1.0)=0$. In accordance with the material and geometric properties used in the numerical method model, commercial (ANSYS) finite element code was compared and generated [31]. Due to the symmetry in the cylinder and sphere, four of the four geometries formed in the finite element model are considered. In the finite element model, an 8-axis axial symmetric rectangular element (Plane82) is used. Because as the density of the element increases in the process of dividing into finite elements, the solution is more meshed by using high density elements in order to obtain the stresses with high accuracy. Since the modulus of elasticity of the FGM cylinder and sphere changes due to a function in the radial direction, it is necessary to distribute it as a function of the radius using the linear distribution of the nodes along the cross-section. By assigning points in the material model window (Elasticity module), ANSYS is provided to express the elasticity module as a function of the radius. A MACRO called a subprogram was used in ANSYS, which automates the assignment process of this radius-elasticity module relationship. For the modeling of the cylindrical and spherical structures FGM, each layer was applied with 20 layers having a fixed material property value.

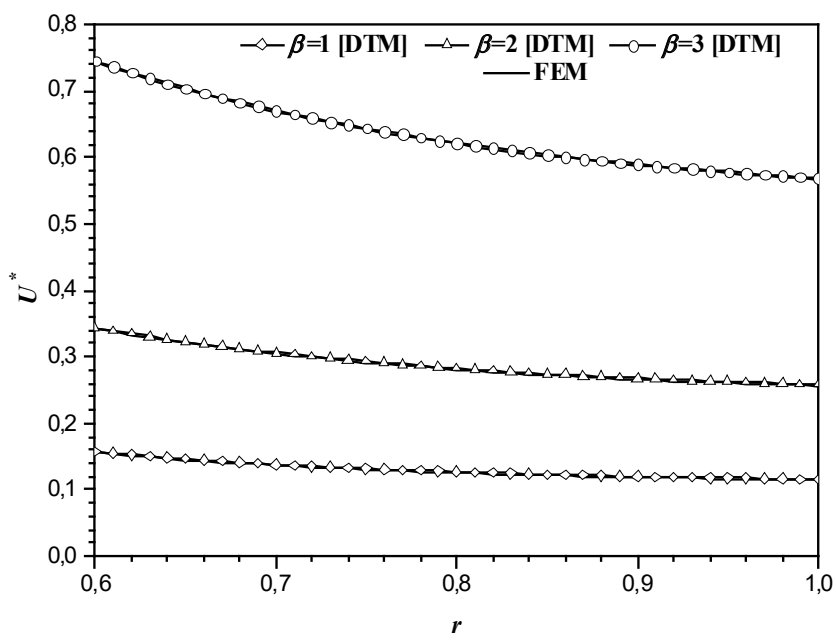

Fig. 1. Displacement of FG cylinder with exponential variable properties

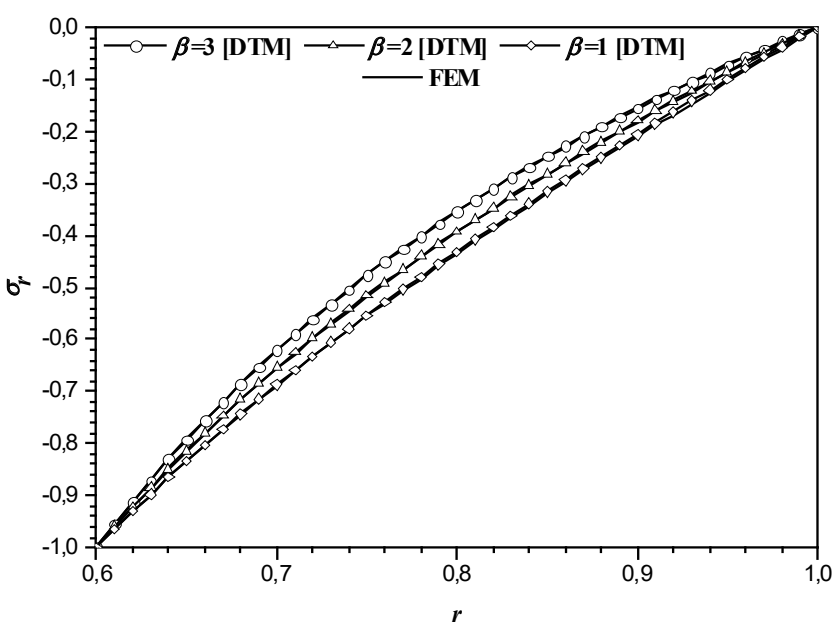

Fig. 2. Radial stresses of FG cylinder with exponential variable properties Positive $\beta$ stands for increased rigidity in the radial direc- 
tion. Fig. 1 shows the displacement of FG cylinder with exponential variable properties. There is a decrease in the value of radial displacement as $\beta$ increases. Fig. 2 illustrates the radial stresses of FG cylinder with exponential variable properties. As $\beta$ increases, a decrease occurs in the value of radial stress. The circumferential stresses of FG cylinder with exponential variable properties is plotted in Fig. 3. Approximately, for $\beta>1$, the hoop stress increases as the radius increases whereas for $\beta<1$ it decreases.

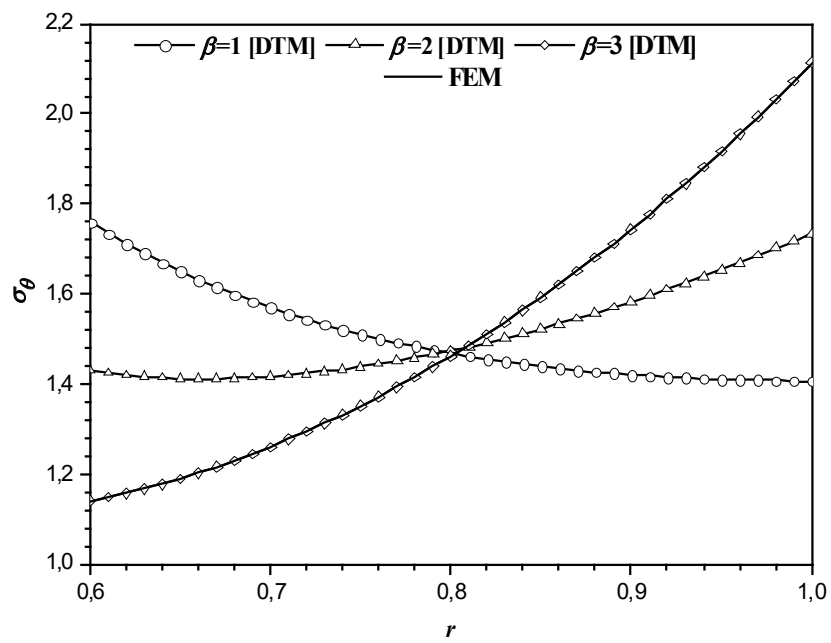

Fig. 3. Circumferential stresses of FG cylinder with exponential variable properties

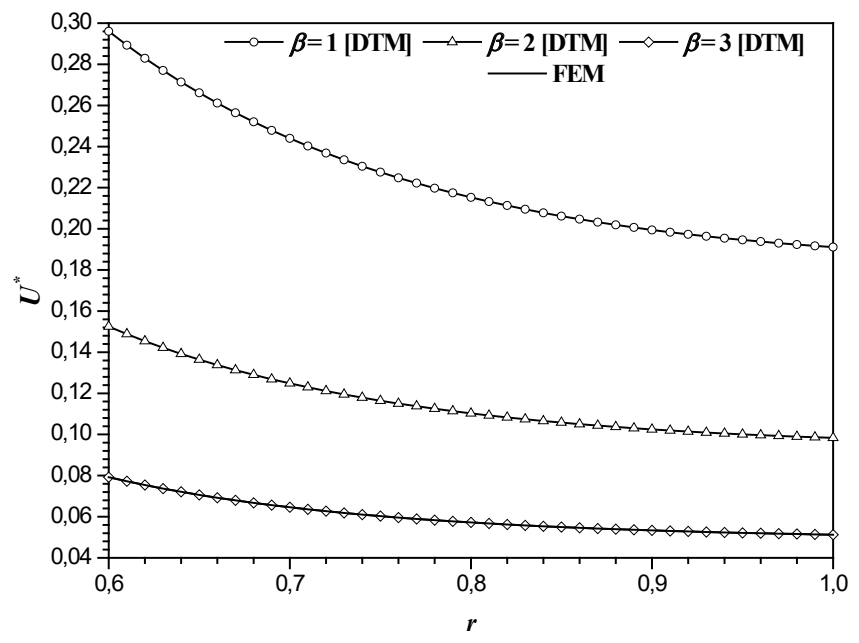

Fig. 4. Displacement of FG sphere with exponential variable properties

Fig. 4 shows displacement of FG sphere with exponential variable properties. It is obvious in this curve that the radial displacement decreases as $\beta$ increases at the same position. In Fig. 5 radial stresses of FG sphere with exponential variable properties is shown. It is perceived that the radial stress increases for higher values of $\beta$. In Fig. 6 circumferential stresses of FG sphere with exponential variable properties for different values of $\beta$ is plotted. Here, it should be noted that in the same situation, approximately, for $r<$ 0.65 , the value of the circumferential stress decreases as $\beta$ increases, whereas for $r<0.65$ this situation was reversed.

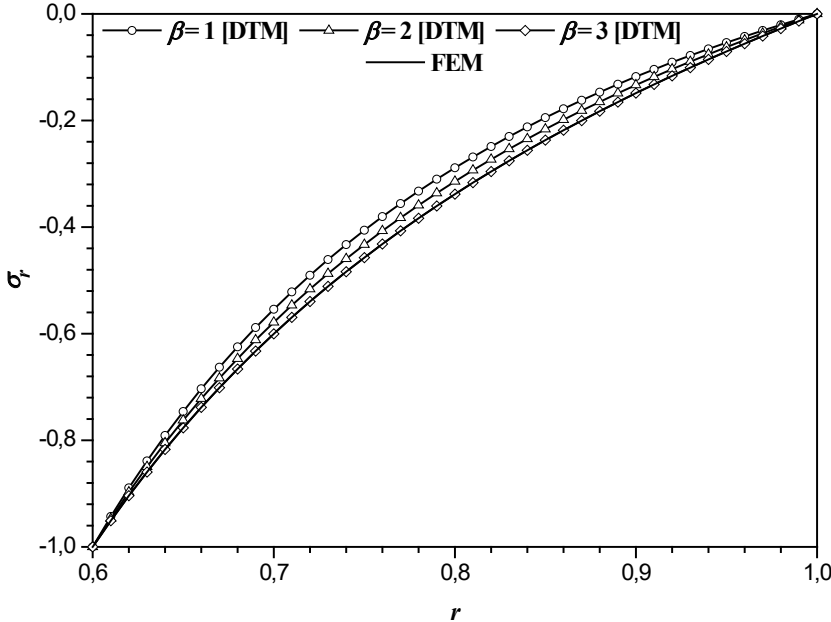

Fig. 5. Radial stresses of FG sphere with exponential variable properties

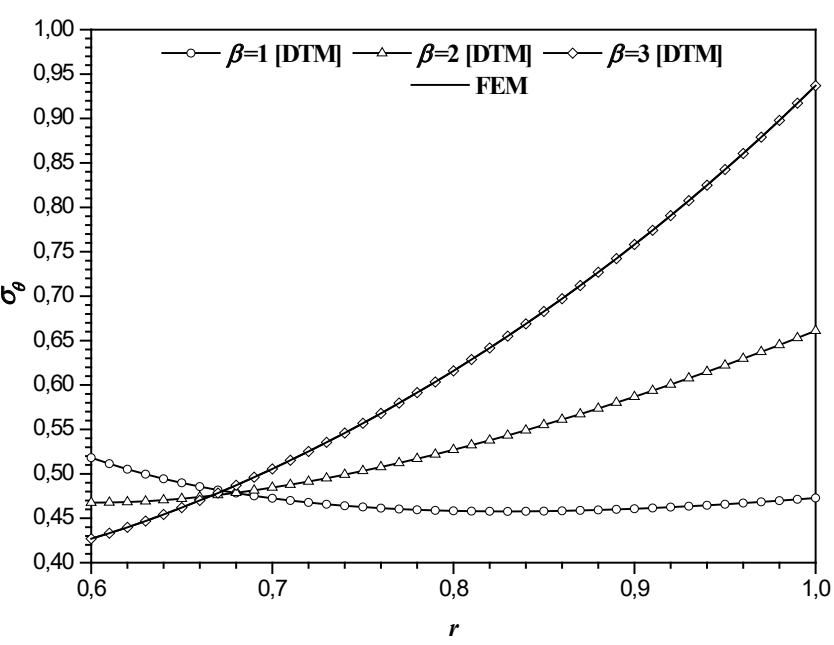

Fig. 6. Circumferential stresses of FG sphere with exponential variable properties

It is seen that the results of DTM solutions are overlapping with the model created using a commercial finite element code, ANSYS [31].

\section{CONCLUSION}

Numerical model of FGM cylinders and spheres for stresses and displacement are obtained and solved by DTM. The efficacy and adequacy of the present method is first compared to analytical results presented for constant Elastic Modulus and Poisson Ratio. The solution procedure can be applied to any continuous grading function option. The solution technique and procedure are simple, efficient and well structured, in addition to providing low cost accuracy. We have seen that FGM thick-walled cylindrical and spherical engineering structures with exponential variable properties have a significant effect on mechanical behavior. In particular, the positive inhomogeneity constant has a major effect on the stress distribution. Although the inhomogeneity parameter is a useful parameter in design, it can be applied for special applications in order to control stress distributions and displacements.

\section{Appendix A. Analytical benchmark solutions}

For a linear elastic material, we know that the exact solution 
of the radial displacement is given by this expression:

$$
u(r)=\left(\frac{p}{E}\right)\left(\frac{a^{2}}{b^{2}-a^{2}}\right)\left[1-v-2 v^{2}+(b / r)^{2}+v(b / r)^{2}\right](\text { A. } 1)
$$

The following expressions are derived for a unit inside pressure for homogeneous cylinder.

$$
u=\frac{r}{\left(R_{0}^{2}-1\right)\left(C_{12}+C_{11}\right)}-\frac{R_{0}{ }^{2} r^{-1}}{\left(R_{0}^{2}-1\right)\left(C_{12}-C_{11}\right)}
$$

Radial stress

$$
\sigma_{r}=\frac{1-R_{0}^{2} r^{-2}}{\left(R_{0}^{2}-1\right)}
$$

Circumferential stress

$$
\sigma_{\theta}=\frac{1-R_{0}^{2} r^{-2}+1}{\left(R_{0}^{2}-1\right)}
$$

\section{REFERENCES}

[1] Tranter, C.J. (1942). The application of the Laplace transformation to a problem on elastic vibrations, Philosophical Magazine,vol. 33, no 223, p.614-22, DOI: 10.1080/14786444208520820.

[2] Mirsky I. (1964). Axisymmetric vibrations of orthotropic cylinders, Journal of the Acoustical Society of America, vol. 36, no 11, p. 210612, DOI: $10.1121 / 1.1919329$

[3] Klosner JM, Dym CL.(1966). Axisymmetric plane-strain dynamic response of a thick orthotropic shell, Journal of the Acoustical Society of America, vol. 39, no 1, p. 1-7, DOl: 10.1121/1.1909869

[4] Ahmed N. (1966). Axisymmetric plane-strain vibrations of a thick-layered orthotropic cylindrical shell, Journal of the Acoustical Society of America, vol. 40, no 6, p. 1509-16, DOl: 10.1121/1.1910256

[5] Ghosh A.K. (1995). Axisymmetric vibration of a long cylinder, Journal of Sound Vibration, vol. 186, no. 5, p. 711-21, DOl: 10.1006/ jsvi.1995.0484

[6] Yıldırım A., Yarımpabuç D., Celebi K. (2019). Thermal stress analysis of functionally graded annular fin, Journal of Thermal Stresses, vol. 42, no. 4, p. 440-451, DOI: 10.1080/01495739.2018.1469963.

[7] Aslan T.A ., Noori A .R., Temel B.(2018) A unified approach for out-of-plane forced vi- bration of axially functionally graded circular rods, European Mechanical Science vol.2, no. 2,p. 37-45, DOI: 10.26701/ems.374524.

[8] Yarımpabuç D., Eker M., Çelebi K. (2018). Forced vibration analysis of non-uniform piezoelectric rod by complementary functions method, Karaelmas Science and Engineering Journal, vol. 8, no. 4, p. 496-504, DOI: 10.7212\%2Fzkufbd.v8i2.1159.

[9] Celebi K., Yarimpabuc D., and Baran T. (2018). Forced vibration analysis of inhomogeneous rods with non-uniform cross-section, Journal of Engineering Research, vol. 6, no. 3, p. 189-202, DOI: 10.21605/cukurovaummfd.316746

[10] Celebi K., Yarımpabuç D., Tutuncu N. (2018). Free vibration analysis of functionally graded beams using complementary functions method, Archive of Applied Mechanics, vol. 88, no. 5, p. 729-739, DOI: 10.1007/s00419-017-1338-6

[11] Güven U., Baykara C. (2001). On stress distributions in functionally graded isotropic spheres subjected to internal pressure, Mechanic Research Communications, vol. 28, no. 3, p. 277-281, DOl:10.1016/ s0093-6413(01)00174-4.
[12] Tütüncü, N., Öztürk, M. (2001). Exact solutions for stresses in functionally graded pressure vessels, Composites Part B: Engineering, vol. 32, no. 8, p. 683-686, DOI: 10.1016/s1359-8368(01)00041-5.

[13] Horgan C.O., Chan A.M. (1999). The pressurized hollow cylinder or disk problem for functionally graded isotropic linearly elastic materials, Journal of Elasticity, vol. 55, p. 43-59, DOI: 10.1023/A:1007625401963

[14] Obata Y, Noda N. (1994). Steady thermal stressesin a hollow circular cylinder and a hollow sphere of a functionally gradient material, Journal of Thermal Stresses vol. 17, p. 471-87, DOI: $10.1080 / 01495739408946273$.

[15] Tutuncu, N., Temel, B. (2009). A novel approach to stress analysis of pressurized FGM cylinders, disks and spheres, Composite Structures, vol. 91, no. 3, p. 385-390, DOI: 10.1016/..compstruct.2009.06.009.

[16] Zhou J.K. (1986), Differential Transformation and Its Applications for Electrical Circuits, Huazhong University Press, Wuhan, China.

[17] Arikoglu A., Ozkol I. (2005). Solution of boundary value problems for integrodifferential equations by using differential transform method, Applied Mathematics and Computation, vol. 168, no. 2. p. 1145-1158, DOl: 10.1016/j.amc.2004.10.009.

[18] Chen C. K., Ho S. H. (1998). Application of differential transformation to eigenvalue problems, Applied Mathematics and Computation, vol. 79, no. 2-3, p. 173-188,DOl: 10.1016/0096-3003(95)00253-7.

[19] Malik M., Dang H. H. (1998). Vibration analysis of continuous systems by differential transformation, Applied Mathematics and Computation, vol. 96, no. 1, p. 17-26, DOI: 10.1016/500963003(97)10076-5.

[20] Hassan I.H.A-H. (2002). On solving some eigenvalue problems by using a differential transformation", Applied Mathematics and Computation, vol. 127, no. 1, p. 1- 22, DOI: 10.1016/S00963003(00)00123-5.

[21] Yeh Y. L., Jang M. J., Wang C. C. (2006). Analyzing the free vibrations of a plate using finite difference and differential transformation method, Applied Mathematics and Computation, vol. 178, no. 2, p. 493-501, DOI: 10.1016/j.amc.2005.11.068 (2006).

[22] Yeh Y. L., Wang C. C., Jang M. J. (2007). Using finite difference and differential transformation method to analyze of large deflections of orthotropic rectangular plate problem, Applied Mathematics and Computation, vol. 190, no. 2, p. 1146-1156, DOI: 10.1016/j. amc.2007.01.099

[23] Shin Y. J., Kwon K. M., Yun J. H. Vibration analysis of a circular arch with variable cross-section using differential transformation and generalized differential quadrature, Journal of Sound and Vibration, vol. 309, no. 1-2, p. 9-19, DOl: 10.1016/j.jsv.2006.08.020.

[24] Chen C.J., Wu W.J. (1996). Application of the Taylor differential transformation method to viscous damped vibration of hard and soft spring system. Computers \& Structures, vol. 59, no. 4, p. 631639, DOl: 10.1016/0045-7949(95)00304-5.

[25] Chen C.K., Ho S.H.(1999). Solving partial differential equations by two-dimensional differential transform method, Applied Mathematics and Computation, vol. 106, no. 2-3, p. 171-179, DOl: 10.1016/S0096-3003(98)10115-7.

[26] Hassan I.H.A-H. (2002). Different applications for the differential transformation in the differential equations, Applied Mathematics and Computation, vol. 129, no. 2-3, p. 183 - 201, DOI: 10.1016/ S0096-3003(01)00037-6

[27] Erturk V. S., Momani S. (2007). A reliable algorithm for solving tenth-order boundary value problems, Numerical Algorithms, vol. 
44, no.2, p. 147-158, DOl: 10.1007/s11075-007-9093-3.

[28] Arikoglu A., Ozkol I. (2006), Solution of difference equations by using differential transform method, Applied Mathematics and Computation, vo. 174, no. 2, p. 1216-1228, DOI: 10.1016/j.amc.2005.06.013.

[29] Rashidi M.M., Erfani E. (2011). A new analytical study of MHD stagnation-point flow in porous media with heat transfer, Computres \& Fluids, vol. 40, p. 172-178, DOI: 10.1016/j.compfluid.2010.08.021.

[30] Ni Q., Zhang Z.L., Wang L. (2011). Application of the differential transformation method to vibration analysis of pipes conveying fluid, Applied Mathematics and Computation, vol. 217, no. 16, p. 7028-7038, DOI: 10.1016/j.amc.2011.01.116.

[31] ANSYS Swanson Analysis System, Inc., 201 Johnson Road, Houston, PA 15342-1300, USA. 